\title{
Distinguishing Environmental Causes of Immune Dysfunction from Pediatric Triggers of Disease
}

\author{
Rodney R. Dietert ${ }^{*}$
}

Department of Microbiology and Immunology, Cornell University, Ithaca, NY 14853, USA

\begin{abstract}
Many pediatric diseases are linked to underlying immune dysfunction that produces problematic responses to common infectious challenges and other conditions. During childhood, immune dysfunction manifests as: 1) increased susceptibility to certain infections, 2) misregulated inflammation with tissue damage, fatigue and secondary infections, 3) autoimmune disease and 4) allergic conditions. Both environmental and genetic risk factors contribute to a variety of pediatric immune-related illnesses. Ironically, the environmental risk factors are usually considered as one large continuum of equivalent chemical, physical and emotional factors spanning the entirety of a child's development. But the reality is that some prenatal and neonatal environmental factors are most likely to cause the underlying pediatric immune dysfunction necessary for inflammatory, autoimmune and allergic disease. In contrast, other childhood environmental factors are usually triggers that activate or challenge the dysfunctional immune system leading directly to disease. Exposure to these triggers represents a final step in the overall disease process. Knowledge of both the causative agents for immune dysfunction as well as the triggering factors is important. However, viewing these prenatal and childhood factors as one continuum of risk is not always helpful. These distinct groups of environmental factors need to be recognized separately if prevention of immune dysfunction and management of immune-based diseases are to be optimized. This mini-review provides a unifying hypothesis concerning causative environmental factors $v s$ triggering events for several important pediatric diseases. Improved recognition of these different steps should help pediatricians to better address these diseases.
\end{abstract}

\section{INTRODUCTION}

Childhood diseases linked with immune dysfunction impact more than $25 \%$ of all children in many developed countries [1]. These diseases include: asthma, allergic rhinitis, atopic dermatitis, food allergies, recurrent otitis media, type 1 diabetes, pediatric Celiac disease, autoimmune thyroiditis, juvenile arthritis and late-onset sepsis. Even relatively complex conditions such as childhood obesity, sleep disorders and psychiatric manifestations appear to involve misregulation of inflammation as an important factor in the etiology of the condition. It should be noted that these diseases are the very ones that have increased in prevalence in recent decades. For this reason, more effective identification and avoidance of disease risks coupled with improved therapeutic approaches for these diseases is needed.

All of these diseases and conditions are known to have environmental risk factors that, along with genetic background, contribute to a child's risk of the disease. For some of these immune-related diseases (e.g., childhood asthma), several risk factors have been established such as maternal smoking, environmental pollutants and drugs [2-5]. But for others (e.g., Kawasaki disease), the environmental risk factors are largely unknown.

This mini-review examines the hypothesis that environmental risk factors may be divided into different

*Address correspondence to this author at the Department of Microbiology and Immunology, C5-135 VMC, Cornell University, North Tower Rd., Ithaca, NY 14853, USA; Tel: 607 253-4015; Fax: 607 253-3384;

E-mail: rrd1@cornell.edu categories: 1) those that cause pediatric immune dysfunction and 2) those that trigger individual pediatric- and/or adultonset diseases. There is merit in recognizing these distinctions. For example, by viewing these environmental risk factors as having distinctly different roles in the progression to pediatric disease, we can more effectively manage the risks faced by the developing immune system.

\section{UNIQUE VULNERABILITIES DURING CHILDHOOD}

The prenatal and early childhood periods of development are critical periods of immune vulnerability not only for pediatric-onset diseases, but also for immune- and inflammation-related diseases that are usually diagnosed in the adult (e.g., multiple sclerosis, atherosclerosis, systemic lupus erythematosus). It is during the prenatal and neonatal periods that one-time immune maturation events occur. These can affect the integrity of the child's capacity to fight infections and cancer, maintain organ homeostasis, utilize but control inflammation and mount an immune response against those challenges that are actually a health threat as opposed to common environmental or food allergens.

\section{TWO CATEGORIES OF IMMUNE RISK FACTORS}

Most environmental factors found to be associated with immune-related diseases are grouped together in one category where they are identified simply as "risk factors". But this grouping, while convenient, has a significant liability. In reality, the contributions of these factors to a given disease such as childhood asthma can be strikingly different. Some factors like maternal smoking cause exposure of the developing immune system to numerous known immunotoxicants ranging from heavy metals and 
benzene to polyaromatic hydrocarbons and nicotine. Such exposure during key periods of immune maturation can profoundly alter the status of the immune system in the child. Significant exposure to these immunotoxicants in early life causes immune dysfunction, and that immune dysfunction can serve as the basis for increased risks for numerous diseases over the course of a lifetime. Factors like maternal smoking are causative agents for pediatric immune dysfunction that can lead not only to asthma but to a matrix of chronic diseases over the entire lifespan [1].

An equally important yet distinct group of environmental risk factors might have the potential to cause immune dysfunction. However, they do not have to cause immune dysfunction to facilitate immune-related pediatric disease. Exposure to these environmental factors is usually after birth, most often in childhood. But they can also act in later life. Instead of contributing to disease by profoundly altering the course of immune development, these environmental factors act in the child in such a way that they reveal the previous environmentally- and/or genetically-established underlying immune dysfunction. In doing so, they become the pivotal childhood triggers for the immune-related disease. This second category of environmental risk factors, the triggers, is often the most easily identified by parents and pediatricians. The reason? They may be the last environmental exposure or event of note prior to immunerelated-disease onset.

For example, influenza infection in some children can be the prelude to secondary bacterial pneumonitis. But does it cause this? Evidence suggests that immature innate immunity and misregulated inflammatory cell responses in the airways during influenza infection initiates a cascade that frequently ends in secondary bacterial infection often requiring antibiotic treatment $[6,7]$. The reason the response to influenza is inappropriate is not due inherently to the viral infection. Instead, it is a reflection of the status of the child's immune system. That status is established earlier in life through the combination of environmental conditions and inherited genetic polymorphisms. The viral infection reveals the immune dysfunction with one or more additional childhood diseases as the outcome of the viral infection.

\section{IMPRINTING THE CHILD'S IMMUNE SYSTEM FOR LATER TRIGGERING}

To trigger an inappropriate immune response, the basis for the dysfunctional response must first be established or imprinted into the developing immune system. In the case with influenza infection inducing bacterial pneumonitis, some of the best evidence of this imprinting comes from an experimental influenza model. When mice were given a single in utero exposure to the potent immunotoxicant, $2,3,7,8$ tetrachlordibenzo-p-dioxin (TCDD), the subsequent offspring mounted a dysfunctional airway response to influenza challenge that included overproduction of proinflammatory cytokines and damage to the epithelial lining well in excess of that seen in the normal course of the influenza infection in control mice [8]. The TCDD exposure imprinted the developing immune system with a hyperinflammatory response that was set to be triggered or revealed whenever the viral airway challenge occurred. In this example, TCDD was the prenatal causative agent of the underlying immune dysfunction, and influenza infection was the postnatal trigger that compromised the airways via inappropriate host immune responses. Genetic background is an additional factor for consideration since the aryl hydrocarbon receptor (AhR) is important in TCDD-induced immunotoxicity and genetic polymophisms exist relative to the AhR The type of misregulated inflammatory response seen in the TCDD-treated influenza-infected mice is similar to that observed by Sun and Metzger [9] as predisposing the lung for bacterial pneumonitis.

In another example comparing causative and triggering factors, this time in children, exposure to maternal smoking [10] or elevated traffic pollution during pregnancy [11] was found to alter the immune system in a predictable manner and appears to represent causative risk factors for childhood asthma.

Other environmental risk factors, and particularly important in asthma, are severe and/or repeated respiratory syncytial virus (RSV) infection or rhinovirus infection with wheezing. These are signals for the likely development of asthma in children. But RSV infection does not produce asthma in every child. In fact, it leads to asthma only in those children with problematic immune responses to the infection. Similarly, infants with certain environmentally-induced and/or genetically- predisposed immune dysfunctions appear to respond differently to rhinovirus infection compared with normal infants [12-14]. In these children, innate immune responses are altered, $\mathrm{T}$ helper 2 (Th2) cytokines are preferentially produced and the rhinovirus infections are more severe and are associated with wheezing [15]. This population of young children was found to have a higher risk for asthma at both age 3 and age 6 compared with the normal population of children [16]. Taken together, the findings suggest that infection by RSV and rhinovirus is probably not a strong causative agent for childhood asthma. Instead, the infectious agents are potent and important triggers of the disease among those infants who have environmentallydriven and/or genetically-determined immune dysfunction. Just as in the case of TCDD and influenza, the RSV and rhinovirus infections reveal those young children who have an immune system that has been imprinted for a specific type of dysfunctional immune response when challenged. The dysfunctional immune response to RSV in the airways is a final step toward asthma and childhood wheezing.

In the prior two examples, the infectious agents are critical factors in the pathway leading to pediatric disease. But they are not in any way equivalent to TCDD or maternal smoking in their effects on the immune system. This distinction has ramifications when it comes to the prevention of disease. Avoiding the infections or minimizing their impact during a window of pediatric development might influence the risk of the immediate disease. But it might not have any effect on the underlying immune dysfunction that can persist into later life. In contrast, avoiding in utero exposure to TCDD or cigarette smoke might alter the risk for pediatric and adult diseases connected to dysfunctional immune responses. The temporal relationships among environmental causes, triggers and selected pediatric diseases are illustrated in Fig. (1). 


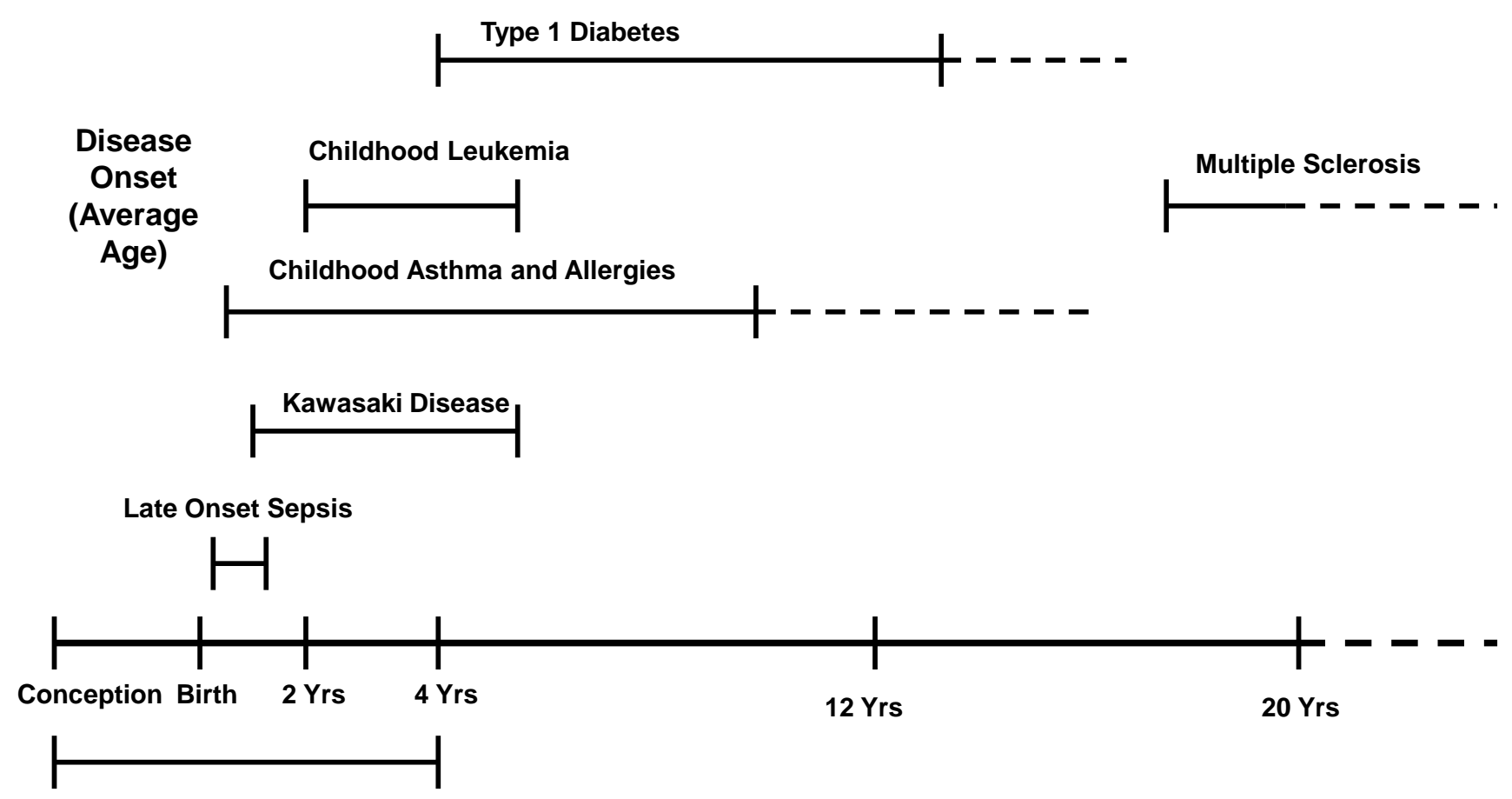

Primary Window: Causes of Immune Dysfunction

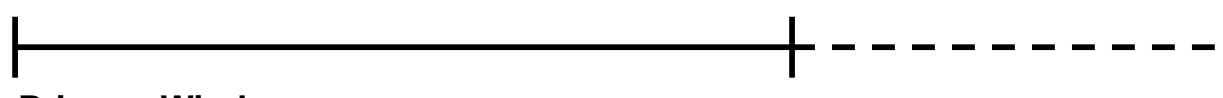

Primary Window: Triggers of Immune-Related Disease

Fig. (1). The diagram illustrates the temporal relationships between 1) causes of immune dysfunction, 2) triggers of immune-related disease and the pediatric diseases organized by age of onset. A timeline from conception throughout childhood development is shown in the center. Below the timeline are the primary prenatal and postnatal windows for: 1) environmental causes of pediatric immune dysfunction and 2) triggers of pediatric immune-related disease. Examples of immune-related diseases are illustrated above the timeline with the approximate predominant ages of onset shown by the solid lines.

\section{EXAMPLES OF OTHER CAUSATIVE AGENTS VS TRIGGERS OF DISEASE}

Table 1 illustrates pediatric and young adult-onset diseases that have established or suspected causative environmental factors from immune dysfunction and environmental factors that trigger disease onset. The table includes examples beyond those previously discussed.

It should be noted that the diseases and conditions in Table $\mathbf{1}$ include several categories of diseases including allergic diseases, infections, autoimmune manifestations and multisystem inflammatory conditions. Among these categories are a significant range of those diseases encountered by the pediatrician.

One of the multifactorial diseases of interest is childhood leukemia and in particular childhood acute lymphoblastic leukemia (cALL). This disease is thought to involve a dysfunctional immune response to common childhood infections as the final step in a lengthy process $[17,18]$. Supporting evidence for this is that vaccination with haemophillus influenzae B (Hib) is protective against childhood leukemia [19]. So the neonatal immune system of some children appears to be primed to be driven toward or away from leukemia based on childhood infections and vaccinations. But as before, postnatal infection/vaccination is apparently the trigger. The immune dysfunction imprinting event probably occurs in utero and involves other risk factors like maternal alcohol consumption [20].

Among the diseases included in Table $\mathbf{1}$ is type 1 diabetes. Presently known environmental risk factors for this disease cannot account for the disease prevalence. However, one of the suggested risk factors for this disease is insufficient intake of Vitamin D. Reduced prenatal and early neonatal Vitamin D levels have been associated with risk of type 1 diabetes. Vitamin D is known to affect the immune system as well as several other physiological systems. One effect of reduced early-life vitamin D intake is an increased susceptibility to infections. Consistent with this, one of the postnatal risk factors for type 1 diabetes is infection with enteroviruses [21-23]. In contrast, other infectious agents may help to protect against the disease [24, 25]. As with the example of asthma, it appears that one set of factors can cause immune problems that are then revealed by certain categories of childhood infections.

Another prominent association in Table $\mathbf{1}$ pertains to exposure to polychlorinated biphenyls (PCBs) in utero and two 
Table 1. Causes $v$ s Triggers for Immune- and Inflammation-Related Diseases

\begin{tabular}{|c|c|c|c|}
\hline Disease or Condition & Putative Immune Risk Factor(s) & Potential Pediatric Trigger(s)/Indicator(s) & References \\
\hline Asthma & Tobacco smoke; Traffic pollution & $\begin{array}{l}\text { Respiratory syncytial virus and rhinovirus } \\
\text { infections }\end{array}$ & {$[10-17,44,45]$} \\
\hline Risk of bacterial pneumonitis* & $\begin{array}{l}\text { 2,3,7,8-tetrachlorodibenzo-p-dioxin } \\
\text { (TCDD) }\end{array}$ & Influenza & {$[8,9]$} \\
\hline $\begin{array}{l}\text { Childhood acute lymphoblastic } \\
\text { leukemia }\end{array}$ & $\begin{array}{l}\text { Maternal alcohol consumption; High } \\
\text { birth weight }\end{array}$ & Childhood infection and vaccination status** & {$[17,19,20,46,47]$} \\
\hline Childhood obesity & $\begin{array}{l}\text { Maternal smoking; Maternal } \\
\text { autoimmune-promoted intrautarine } \\
\text { inflammation; birth weight }\end{array}$ & Formula-feeding of infants; Sleep problems & {$[48-54]$} \\
\hline Juvenile arthritis (girls) & Maternal smoking & Infections in first year of life & {$[55,56]$} \\
\hline Kawasaki disease & $\begin{array}{l}\text { Unknown environmental and genetic } \\
\text { factors }\end{array}$ & Infectious agents & [57] \\
\hline Multiple sclerosis & Low childhood Vitamin D & $\begin{array}{c}\text { Viral infection (e.g., Epstein-Barr virus, } \\
\text { others) }\end{array}$ & {$[58-60]$} \\
\hline Myalgic encephalomyelitis & Childhood trauma, other? & Infections and stress & {$[32,61-65]$} \\
\hline Otitis media & Polychlorinated biphenyls & Streptococcal and other bacteria & {$[26,66]$} \\
\hline $\begin{array}{l}\text { Reduced vaccine responses } \\
\quad \text { (unprotective levels) }\end{array}$ & Polychlorinated biphenyls & Childhood vaccinations & [29] \\
\hline Type 1 diabetes & $\begin{array}{c}\text { Seasonality of Birth; Low perinatal- } \\
\text { neonatal Vitamin D }\end{array}$ & Enterovirus infection & {$[23,67-69]$} \\
\hline
\end{tabular}

* Results from rodents studies.

** Hib vaccination was reported to be protective.

different childhood health problems. In one case, prenatal-early neonatal exposure to PCBs predisposed children for otitis media infections. The infectious agents associated with otitis media including streptococcal bacteria were the disease instigators. But it is the underlying PCB-induced immune dysfunction that altered host resistance. The association of PCBs to otitis media was reported both in the Canadian Inuit population [26] and among Dutch schoolchildren [27] and to an increase in respiratory infections among Swedish children [28]. A second example illustrates that PCB exposure shifts the developing immune system to a dysfunctional state. Faroe Island children with the highest in utero PCB exposure failed to mount protective responses to diphtheria-pertussis-tetanus (DPT) vaccination [29]. Antibody responses were inversely correlated with cord blood PCB levels.

While infections or vaccinations represent the majority of the triggering agents shown in Table 1, other factors can also serve as triggers. One example shown is that of pediatric (or adult-onset) myalgic encephalomyelitis [also known as chronic fatigue syndrome (CFS)]. While it involves multiple systems, the disease is characterized by a dysfunctional immune system that includes misregulated inflammatory responses [30, 31]. Many of the early life risk factors for this disease have yet to be defined. But profound childhood stress, as is found with childhood trauma, is common to many of the patients [32]. In this model, it appears that childhood trauma can fix or imprint the immune system for dysfunctional responses. This is consistent with what is known about stress and immune development [33]. Once the imprinting for dysfunction is in place, CFS episodes can be induced by a variety of factors including stress and infection [34-36]. For this reason the detection of viruses often seen in CFS patients [37] is more likely to be a reflection of the underlying immune dysfunction rather than a cause of the condition itself.

The other examples shown in Table $\mathbf{1}$ involve multiple sclerosis, Kawasaki disease and childhood obesity. While the latter is not restricted to the category of an immune-related disease, the connection of misregulated inflammation to childhood obesity seems clear. Low grade inflammation has been closely associated with pediatric obesity [38-40]. For this reason it is worth noting that maternal smoking, the same prenatal factor that affects many of the other immune related diseases, is a predisposing factor in childhood obesity.

\section{EXCEPTIONS TO THE TWO STEP IMMUNE DYSFUNCTION MODEL}

Having described this sequence of prenatal-neonatal developmental immunotoxicity followed by childhood triggers of disease, it is important to consider if exceptions are likely to be found among children. Genetic diversity of children suggests this is likely. Certainly, this would be expected for a small minority of children, those where genetic background would effectively remove them from the impact of certain immune disrupting environmental events. However, the majority of children are likely to be influenced by these immunotoxic and immune triggering environmental agents.

Pediatric asthma provides an opportunity to discuss possible exceptions. Both of these exceptions are based on children having genetic backgrounds where the immune response is already skewed to a polarizing extreme (e.g., highly Th2 or higher Th1 skewed). For example, where both parents are atopic, a child may well inherit alleles that 
predispose for Th2-driven high IgE production and hyperinflammatory responses. These children are already on a probable course for asthma. Therefore, exposure of these children to prenatal/neonatal causative environmental conditions (i.e., high traffic pollution, maternal smoking, in utero vitamin $\mathrm{D}$ deficiency) may be relatively unimportant for the development of pediatric asthma. Only the triggering event in the infant may be important in producing asthma because the immune system is already on a problematic course set by the inheritance of predisposing alleles. In this high-atopy-risk population of children, maternal smoking during pregnancy may not be needed as a prerequisite cause for childhood asthma. However, prenatal exposure to toxicants such as cigarette smoke is still likely to increase the risk of other diseases that should not be ignored (e.g., cardiovascular disease). In this example, geneticallydetermined atopic predisposition may lead to asthma and/or allergies with little else needed. Only if other environmental factors intervene and change the immune maturation process (e.g., maternal diet, specific bacterial stimuli for dendritic cells, drugs) would the course leading to asthma be redirected.

The reverse is also probably true for a handful of children. That is why some children may be relatively resistant to certain kinds of environmentally-induced immune dysfunction. This is supported by susceptibility and resistance patterns observed among different genetic strains of experimental animals. A small minority of babies may be relatively resistant to the path where the combined immune altering effects of traffic pollution and RSV or rhinovirus infection end in asthma. Certainly, not all environmental exposures to toxicants and infectious agents produce the same exact physiological outcome across a genetically diverse population. This effect of genetic heterogeneity is most often recognized in autoimmune diseases where the genetic background of the individual combines with environmental insults to determine the overall risk for a given disease.

Even with these possible exceptions, immune-related diseases have been increasing in prevalence. This suggests that a significant percentage of the pediatric population is affected by environmental agents capable of producing underlying immune dysfunction and elevated risk of pediatric disease. For this reason, the identification of additional hazards for the baby's immune system should be a top priority

\section{IMPEDIMENTS TO IDENTIFYING RISK FACTORS FOR PEDIATRIC IMMUNE DYSFUNCTION}

Most of the risk factors identified to date have come though basic research combined with large scale human epidemiology studies. When it comes to environmental risk of diseases like childhood otitis media, allergic and autoimmune diseases, the track record of safety testing of chemical and drugs and responses by regulatory agencies is questionable at best. In the face of recent safety testing, the prevalence of these diseases has increased, not decreased. The reason for this can be found in the strategies for immune safety testing of chemicals and drugs, which were recently discussed [41, 42]. The three key features of safety testing that impact childhood immune health risks as follows: 1)
Testing for chemical and drug-induced adult immune dysfunction is not routine in safety testing [43]. 2) Testing for prenatal or neonatal immune risk is extremely rare. 3) When developmental immunotoxicity testing is done, the recommended tests are not able to predict risk of allergic and autoimmune diseases. Until current safety testing strategies change to ensure protection of the developing immune system, adequate protection of the child's immune system will remain a significant public health concern.

\section{CONCLUSIONS}

Environmentally-induced immune dysfunction in early life contributes significantly to the prevalence of many pediatric diseases. Most of the diseases are diagnosed shortly after (one month-2 years) exposure to precipitating triggers, although, in some cases, there is a longer interval before disease onset. The environmental triggers are usually encountered during the child's neonatal or adolescent periods. Examples of childhood immune triggers presented in this review include infections and stress.

This mini-review considers a unifying hypothesis. Triggers that reveal a child's dysfunctional immune capacity are usually distinguishable from causative environmental factors. The latter, when combined with genetic background, impair the developing immune system and produce pediatric immune dysfunction. Problematic exposure to these causative factors is more common in utero and during the first 2-4 years of life. Examples of dysfunction-inducing environmental agents discussed in this review are: maternal smoking, traffic pollution, and maternal alcohol consumption, level of maternal intrauterine inflammation and reduced vitamin D levels.

It is useful to distinguish the causative agents from the triggers both in the case of identification and for pursuing potential preventative and therapeutic strategies. Better recognition of these categories of risk factors should help the pediatrician to more effectively manage the child's immune system. Additionally, safety testing that is redirected toward 1) the child, 2) the developing immune system and 3) diseases of greatest pediatric concern should facilitate identification of additional environmental risk factors.

\section{ACKNOWLEDGEMENT}

The author thanks Janice Dietert, Performance Plus Consulting, for her editorial suggestions.
ABBREVIATIONS
cALL = Childhood acute lymphoblastic leukemia
$\mathrm{CFS}=$ Chronic fatigue syndrome
DPT = Dipththria-pertussis-tetanus
$\mathrm{Hib}=$ Haemophillus influenzae $\mathrm{B}$
PCBs = Polychlorinated biphenyls
RSV $=$ Respiratory syncytial virus
TCDD $=2,3,7,8$-Tetrachlorodibenzo-p-dioxin
Th $=$ Thelper
Th1 $1=$ T helper 1
Th2 $=$ Thelper 2 


\section{REFERENCES}

[1] Dietert RR, Zelikoff JT. Pediatric immune dysfunction and health risks following early life immune insult. Curr Pediatr Rev 2009; 5 : 36-51.

[2] Yeatts K, Sly P, Shore S, et al. A brief targeted review of susceptibility factors, environmental exposures, asthma incidence, and recommendations for future asthma incidence research. Environ Health Perspect 2006; 114: 634-40.

[3] Selgrade MK, Lemanske RF Jr, Gilmour MI, et al. Induction of asthma and the environment: what we know and need to know. Environ Health Perspect 2006; 114: 615-9.

[4] Selgrade MK. Immunotoxicity: the risk is real. Toxicol Sci 2007; 100: 328-32.

[5] Dietert RR, Zelikoff JT. Early-life environment, developmental immunotoxicology, and the risk of pediatric allergic disease including asthma. Birth Defects Res B Dev Reprod Toxicol 2008; 83: 547-60.

[6] Smith MW, Schmidt JE, Rehg JE, Orihuela CJ, McCullers JA. Induction of pro- and anti-inflammatory molecules in a mouse model of pneumococcal pneumonia after influenza. Comp Med 2007; 57: 82-9.

[7] Ho LP, Denney L, Luhn K, Teoh D, Clelland C, McMichael AJ. Activation of invariant NKT cells enhances the innate immune response and improves the disease course in influenza A virus infection. Eur J Immunol 2008; 38: 1913-22.

[8] Hogaboam JP, Moore AJ, Lawrence BP. The aryl hydrocarbon receptor affects distinct tissue compartments during ontogeny of the immune system. Toxicol Sci 2008; 102: 160-70.

[9] Sun K, Metzger DW. Inhibition of pulmonary antibacterial defense by interferon-gamma during recovery from influenza infection. Nat Med 2008; 14: 558-64.

[10] Wang L, Pinkerton KE. Air pollutant effects on fetal and early postnatal development. Birth Defects Res C Embryo Today 2007; 81: 144-54.

[11] Mortimer K, Neugebauer R, Lurmann F, Alcorn S, Balmes J, Tager I. Early-lifetime exposure to air pollution and allergic sensitization in children with asthma. J Asthma 2008; 45: 874-81.

[12] Johnson SL. Innate immunity in the pathogenesis of virus-induced asthma exacerbations. Proc Am Thorac Soc 2007; 4: 267-70.

[13] Kelly JT, Busse WW. Host immune response to rhinovirus: mechanisms in asthma. J Allergy Clin Immunol 2008; 122: 671-82.

[14] Martinez FD. The origins of asthma and chronic obstructive pulmonary disease in early life. Proc Am Thorac Soc 2009; 6: 2727.

[15] Walker RP, Johnson SL. Role of respiratory viral infections in the development of atopic conditions. Curr Opin Allergy Clin Immunol 2008; 8: 150-3.

[16] Jackson DJ, Gangnon RE, Evans MD, et al. Wheezing rhinovirus illnesses in early life predict asthma development in high-risk children. Am J Respir Crit Care Med 2008; 78: 67-72.

[17] Greaves M. Infection, immune responses and the aetiology of childhood leukaemia. Nat Rev Cancer 2006; 6: 193-203.

[18] Dietert RR. Developmental immunotoxicity (DIT), postnatal immune dysfunction and childhood leukemia. Blood Cell Mol Dis 2009; 42: 108-12.

[19] Ma X, Does MB, Metayer C, Russo C, Wong A, Buffler PA. Vaccination history and risk of childhood leukaemia. Int $\mathrm{J}$ Epidemiol 2005; 34: 1100-9.

[20] MacArthur AC, McBride ML, Spinelli JJ, Tamaro S, Gallagher RP, Theriault G. Risk of childhood leukemia associated with parental smoking and alcohol consumption prior to conception and during pregnancy: the cross-Canada childhood leukemia study. Cancer Causes Control 2008; 19: 283-95

[21] Elfaitouri A, Berg AK, Frisk G, Yin H, Tuvemo T, Blomberg J. Recent enterovirus infection in type 1 diabetes: evidence with a novel IgM method. J Med Virol 2007; 79: 1861-7.

[22] Jaidane H, Hober D. Role of coxsackievirus B4 in the pathogenesis of type 1 diabetes. Diabetes Med 2008; 34: 537-48.

[23] Drescher KM, Tracy SM. The CVB and etiology of type 1 diabetes. Curr Top Microbiol Immunol 2008; 323: 259-74.

[24] Cooke A. Review series on helminths, immune modulation and the hygiene hypothesis: how might infection modulate the onset of type 1diabetes? Immunology 2009; 126: 12-7.

[25] Cooke A. Infection and autoimmunity. Blood Cells Mol Dis 2009; 42: $105-7$.
[26] Dallaire F, Dewailly E, Vézina C, et al. Effect of prenatal exposure to polychlorinated biphenyls on incidence of acute respiratory infections in preschool Inuit children. Environ Health Perspect 2006; 114: 1301-5.

[27] Weisglas-Kuperus N, Vreugdenhil HJ, Mulder PG. Immunological effects of environmental exposure to polychlorinated biphenyls and dioxins in Dutch school children. Toxicol Lett 2004; 149: 281-5.

[28] Glynn A, Thuvander A, Aune M, et al. Immune cell counts and risks of respiratory infections among infants exposed pre- and postnatally to organochlorine compounds: a prospective study. Environ Health 2008; 7: 62.

[29] Heilmann C, Grandjean P, Weihe P, Nielsen F, Budtz-Jørgensen E. Reduced antibody responses to vaccinations in children exposed to polychlorinated biphenyls. PloS Med 2006; 3: e311.

[30] Dietert RR, Dietert JM. Possible role for early-life immune insult including developmental immunotoxicity in chronic fatigue syndrome (CFS) or myalgic encephalomyelitis (ME). Toxicology 2008; 247: 61-72.

[31] Lorusso L, Mikhaylova SV, Capelli E, Ferrari D, Ngonga GK, Ricevuti G. Immunological aspects of chronic fatigue syndrome. Autoimmun Rev 2009; 8: 287-91.

[32] Heim C, Nater UM, Maloney E, Boneva R, Jones JF, Reeves WC. Childhood trauma and risk for chronic fatigue syndrome: association with neuroendocrine dysfunction. Arch Gen Psychiatry 2009; 66: 72-80.

[33] Bellinger DL, Lubahn C, Lorton D. Maternal and early life stress effects on immune function: relevance to immunotoxicology. J Immunotoxicol 2008; 5: 419-44.

[34] Nijs J, De Meirleir K, Wolfs S, Duquet W. Disability evaluation in chronic fatigue syndrome: associations between exercise capacity and activity limitations/participation restrictions. Clin Rehabil 2004; 18: 139-48.

[35] Gaab J, Rohleder N, Heitz V, et al. Stress-induced changes in LPSinduced pro-inflammatory cytokine production in chronic fatigue syndrome. Psychoneuroendocrinology 2005; 30: 188-98.

[36] Glaser R, Padgett DA, Litsky ML, et al. Stress-associated changes in the steady-state expression of latent Epstein-Barr virus: implications for chronic fatigue syndrome and cancer. Brain Behav Immun 2005; 19: 91-103.

[37] Nicolson GL, Gan R, Haier J. Multiple co-infections (Mycoplasma, Chlamydia, human herpes virus-6) in blood of chronic fatigue syndrome patients: association with signs and symptoms. Acta Pathol Microbiol Immunol Scand 2003; 111: 557-66.

[38] Winer JC, Zern TL, Taksali SE, et al. Adiponectin in childhood and adolescent obesity and its association with inflammatory markers and components of the metabolic syndrome. J Clin Endocrinol Metabol 2006; 91: 4415-23.

[39] Sacheck J. Pediatric obesity: an inflammatory condition? J Parenter Enteral Nutr 2008; 32: 633-7.

[40] Warnberg J, Marcus A. Low-grade inflammation and the metabolic syndrome in children and adolescents. Curr Opin Lipidol 2008; 19 : 11-5.

[41] Dietert RR. Developmental immunotoxicity (DIT) in drug safety testing: matching DIT testing to adverse outcomes and childhood disease risk. Curr Drug Saf 2008; 3: 216-26.

[42] Dietert RR. Developmental immunotoxicology: focus on health risks. Chem Res Toxiol 2009; 22: 17-23.

[43] United States Food and Drug Administration. ICH Guidance for Industry. S8 Immunotoxicity Studies for Human Pharmaceuticals. April 2006.

[44] Monhapatra SS, Bbonyapalle S. Epidemiologic, experimental, and clinical links between respiratory syncytial virus infection and asthma. Clin Microbiol Rev 2008; 21: 495-504.

[45] Stensballe LG, Simonsen JB, Thomsen SF. The causal direction in the association between respiratory syncytial virus hospitalization and asthma. J Allergy Clin Immunol 2009; 123: 131-7.

[46] Menegaux F, Ripert M, Hémon D, Clavel J. Maternal alcohol and coffee drinking, parental smoking and childhood leukaemia: a French population-based case-control study. Paediatr Perinat Epidemiol 2007; 21: 293-9.

[47] Caughey RW, Michels KB. Birth weight and childhood leukemia: a meta-analysis and review of the current evidence. Int $\mathrm{J}$ Cancer 2009; 124: 2658-70.

[48] Koletzko B, von Kries R, Monasterolo RC. Can infant feeding choices modulate later obesity risk? Am J Clin Nutr 2009; 89(5): 1502S-1508S, doi:10.3945/ajen.2009.27113D 
[49] Shehadeh N, Weitzer-Kish H, Shamir R, Shihab S, Weiss R. Impact of early postnatal weight gain and feeding patterns on body mass index in adolescence. J Pediatr Endocrinol Metab 2008; 21: 9-15.

[50] Oyama M, Nakamura K, Tsuchiya Y, Yamamoto M. Unhealthy maternal lifestyle leads to rapid infant weight gain: prevention of future chronic diseases. Tohoku J Exp Med 2009; 217: 67-72.

[51] Jiang F, Zhu S, Yan C, Jin X, Bandla H, Shen X. Sleep and Obesity in Preschool Children. J Pediatr 2009; [Epub ahead of print].

[52] Touchette E, Petit D, Tremblay RE, et al. Associations between sleep duration patterns and overweight/obesity at age 6. Sleep 2008; 31: 1507-14.

[53] Singhal A. Does breastfeeding protect from growth acceleration and later obesity? Nestle Nutr Workshop Ser Pediatr Program 2007; 60: 15-25.

[54] Nelson SM, Sattar N, Freeman DJ, Walker JD, Lindsay RS. Inflammation and endothelial activation is evident at birth in offspring of mothers with type 1 diabetes. Diabetes 2007; 56: 2697 704.

[55] Jaakkola JJ, Gissler M. Maternal smoking in pregnancy as a determinant of rheumatoid arthritis and other inflammatory polyarthropathies during the first 7 years of life. Int J Epidemiol 2005; 34: 664-71.

[56] Carlens C, Jacobsson LT, Brandt L, Cnattingius S, Stephansson O, Askling J. Perinatal characteristics, early life infections, and later risk of rheumatoid arthritis and juvenile idiopathic arthritis. Ann Rheum Dis 2008; [Epub ahead of print].

[57] Kao AS, Getis A, Brodine S, Burns JC. Spatial and temporal clustering of Kawasaki syndrome cases. Pediatr Infect Dis J 2008; 27: 981-5.

[58] Correale J, Ysrraelit MC, Gaitán MI. Immunomodulatory effects of Vitamin D in multiple sclerosis. Brain 2009; [Epub ahead of print].

[59] Kampman MT, Brustad M. Vitamin D: a candidate for the environmental effect in multiple sclerosis - observations from Norway. Neuroepidemiology 2008; 30: 140-6.
[60] Salvetti M, Giovannoni G, Aloisi F. Epstein-Barr virus and multiple sclerosis. Curr Opin Neurol 2009; [Epub ahead of print].

[61] Maes M. Inflammatory and oxidative and nitrosative stress pathways underpinning chronic fatigue, somatization and psychosomatic symptoms. Curr Opin Psychiatry 2009; 22: 75-83.

[62] Wyller VB, Barbieri R, Thaulow E, Saul JP. Can sustained arousal explain the Chronic Fatigue Syndrome? Behav Brain Funct 2009; 5: 10 .

[63] Faulkner S, Smith A. A longitudinal study of the relationship between psychological distress and recurrence of upper respiratory tract infections in chronic fatigue syndrome. $\mathrm{Br} \mathrm{J}$ Health Psychol 2008; 131: 77-86.

[64] Maes M, Coucke F, Leunis JC. Normalization of the increased translocation of endotoxin from gram negative enterobacteria (leaky gut) is accompanied by a remission of chronic fatigue syndrome. Neuro Endocrinol Lett 2007; 28: 739-44.

[65] Elena Garralda M, Chalder T. Practitioner review: chronic fatigue syndrome in childhood. J Child Psychol Psychiatry 2005; 46: 114351 .

[66] Vergison A. Microbiology of otitis media: a moving target. Vaccine 2008; 26(Suppl 7): G5-10.

[67] Mohr SB, Garland CF, Gorham ED, Garland FC. The association between ultraviolet $\mathrm{B}$ irradiance, vitamin $\mathrm{D}$ status and incidence rates of type 1 diabetes in 51 regions worldwide. Diabetologia 2008; 51: 1391-8.

[68] Bener A, Alsaied A, Al-Ali M, et al. High prevalence of vitamin D deficiency in type 1 diabetes mellitus and healthy children. Acta Diabetol 2008; [Epub ahead of print].

[69] Lewy H, Hampe CS, Kordonouri O, et al. Seasonality of month of birth differs between type 1 diabetes patients with pronounced beta-cell autoimmunity and individuals with lesser or no beta-cell autoimmunity. Pediatr Diabetes 2008; 9: 46-52.

(C) Rodney R. Dietert; Licensee Bentham Open.

This is an open access article licensed under the terms of the Creative Commons Attribution Non-Commercial License (http://creativecommons.org/licenses/by$\mathrm{nc} / 3.0 /$ ) which permits unrestricted, non-commercial use, distribution and reproduction in any medium, provided the work is properly cited. 